\title{
Furosemide and albumin for diuresis of edema (FADE): a study protocol for a randomized controlled trial
}

\author{
Simon JW Oczkowski ${ }^{1,2^{*}}$, lan Mazzetti ${ }^{1}$, Maureen O Meade ${ }^{1}$ and Cindy Hamielec ${ }^{1}$
}

\begin{abstract}
Background: Fluid retention is a common complication of critical illness. It typically results from large-volume fluid infusions during acute resuscitation and is worsened by hypoalbuminemia. Recognized as edema, fluid retention is important for its association with delayed weaning and increased mortality. The standard treatment is the administration of diuretics, with or without albumin. We hypothesize that intravenous $25 \%$ albumin plus furosemide, by comparison with furosemide alone, improves diuresis, oxygenation, and hemodynamic stability in the deresuscitation of critically ill, hypoalbuminemic patients. We propose a pilot study to determine the feasibility of a trial to investigate this hypothesis.
\end{abstract}

Methods/Design: FADE is a single-center, parallel, pilot randomized controlled trial. We aim to allocate 50 hemodynamically stable, hypoalbuminemic adult patients receiving diuresis to treatment with either $100 \mathrm{ml}$ of either $25 \%$ albumin or normal saline placebo twice daily, for a total of six doses. Diuretics are to be prescribed by the caregiving team at least twice daily, and administered within 2 hours following study treatment. Patients, intensive care unit (ICU) clinicians, data collectors, and outcome adjudicators will be blinded to treatment allocation. Feasibility outcome measures include the proportion of patients receiving albumin within 2 hours of diuretic, the proportion of patients receiving the full six doses of study treatment, the proportion of patients who receive open label $25 \%$ albumin, and the rate of recruitment. Physiologic, laboratory, and clinical data are collected until discharge from the ICU or until 30 days.

Discussion: This is the first randomized trial to assess the use of hyperoncotic albumin in addition to diuretics in a general ICU population. Should this pilot study demonstrate feasibility, the primary outcome measure of the larger clinical trial will be the number of ventilator-free days, with secondary clinical outcome measures of duration of mechanical ventilation, length of ICU stay, episodes of hemodynamic instability and mortality. The addition of 25\% albumin to standard diuretic therapy is a promising treatment in the post-resuscitation care of the critically ill patient.

Trial registration: ClinicalTrials.gov NCT02055872; ISRCTN70191881.

Keywords: Albumin, Critical care, Edema, Furosemide, Diuresis, Post-resuscitation

\footnotetext{
* Correspondence: simon.oczkowski@medportal.ca

${ }^{1}$ Division of Critical Care Medicine, McMaster University, Hamilton, ON,

Canada

${ }^{2}$ Critical Care Medicine Residency Program, Room $2 \mathrm{U}$ c/o Anesthesia

Department, McMaster University, 1200 Main St. W., Hamilton, ON L8N 3Z5,

Canada
}

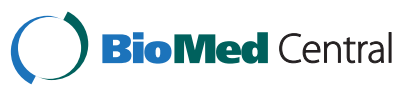

(c) 2014 Oczkowski et al.; licensee BioMed Central Ltd. This is an Open Access article distributed under the terms of the Creative Commons Attribution License (http://creativecommons.org/licenses/by/4.0), which permits unrestricted use, distribution, and reproduction in any medium, provided the original work is properly credited. The Creative Commons Public Domain Dedication waiver (http://creativecommons.org/publicdomain/zero/1.0/) applies to the data made available in this article, unless otherwise stated. 


\section{Background}

\section{Study rationale}

Many intensive care unit (ICU) patients require fluid resuscitation with crystalloids, colloids, or blood products in order to treat their critical illness. However, aggressive resuscitation can lead to fluid overload, characterized by peripheral and pulmonary edema, and has been associated with the development of acute respiratory distress syndrome (ARDS) and longer stays in the ICU, as well as higher mortality, compared with patients without fluid overload [1-3]. Observational data suggest that positive fluid balance is among the most important prognostic variables for ICU mortality [4], and a retrospective review of the use of intravenous fluids during the first four days of sepsis care in the VASST study showed that a more positive fluid balance at both 12 hours and day 4 correlated significantly with mortality [2]. In the ARDS population, positive fluid balance in addition to a high tidal volume ventilatory strategy is associated with worse outcomes [3], and randomized controlled trial data from Wheeler et al. [5] has shown a conservative intravenous fluid strategy to be of benefit with respect to improved lung function and duration of mechanical ventilation strategy in a broad population with ARDS. More recent data have suggested that in patients with acute lung injury complicating septic shock, adequate initial fluid resuscitation coupled with conservative late fluid management results in optimal outcomes [6]. Thus, in ICU patients without shock, maintenance of euvolemia and diuresis of excess fluid received during initial resuscitation may be beneficial, with loop diuretics such as furosemide being the standard therapy.
At the same time, critical illness and malnutrition can lead to hypoproteinemia, resulting in lower vascular oncotic pressure and a tendency for fluid to shift into the interstitial compartment, further worsening edema [7]. For such patients, a strategy of hyperoncotic colloid infusion followed by a diuretic such as furosemide makes physiologic sense, as the colloid promotes redistribution of fluid from edematous peripheral tissues back into the vascular compartment, where it can then be filtered and excreted by the kidneys. Research from our institution has confirmed that hyperoncotic albumin can improve colloid osmotic pressure in critically ill patients [8]. Furthermore, furosemide itself is heavily protein-bound, and in hypoproteinemic patients this results in an increased volume of distribution and lower concentrations of the diuretic in the loop of Henle [9]. The addition of albumin to furosemide has been shown to improve the volume of diuresis in several patient populations, including patients with renal failure [10-12], and cirrhosis [13].

Thus, in critically ill patients with hypoproteinemia and evidence of volume overload, there is a rationale for studying the addition of colloids to standard diuretic therapy. Despite this, there are few prospective studies, and only two randomized controlled trials, which have evaluated the addition of colloids to diuretics in critically ill patients (Table 1) [14-17]. Both randomized controlled trials evaluated the use of albumin in addition to furosemide. Makhoul and colleagues [18] randomized 30 mechanically ventilated patients with congestive heart failure to intravenous furosemide with or without $25 \%$ albumin, and did not demonstrate a difference in volume

Table 1 Studies evaluating $25 \%$ albumin vs. placebo for the diuresis of critically ill patients

\begin{tabular}{|c|c|c|c|c|}
\hline Reference & Type of study & Study population & Study intervention & Study outcome \\
\hline$[14]$ & Non-randomized trial & Surgical ICU patients & $\begin{array}{l}\text { Salt-poor albumin }(n=8) \text { versus } \\
\text { furosemide alone }(n=5) \text {; all } \\
\text { patients received furosemide }\end{array}$ & $\begin{array}{l}\text { Improved oxygenation as } \\
\text { measured by } \mathrm{ADO}_{2} \text { at } 2 \text { hours }\end{array}$ \\
\hline$[17]$ & $\begin{array}{l}\text { Retrospective } \\
\text { observational study }\end{array}$ & Medical ICU patients $(n=31)$ & $\begin{array}{l}\text { Case patients received } 25 \% \text { albumin; } \\
\text { control patients did not; all patients } \\
\text { received furosemide infusion }\end{array}$ & $\begin{array}{l}\text { No change in urine output } \\
\text { or fluid balance }\end{array}$ \\
\hline$[18]$ & $\begin{array}{l}\text { Randomized } \\
\text { controlled trial }\end{array}$ & $\begin{array}{l}\text { Mechanically ventilated } \\
\text { patients with congestive } \\
\text { heart failure }(n=30)\end{array}$ & $\begin{array}{l}250 \mathrm{mg} \text { frusemide diluted in } \\
12.5 \mathrm{~g} \text { albumin at a rate of } 0.1 \mathrm{mg} \\
\text { frusemide/ } \mathrm{kg} / \mathrm{hour} \text { versus furosemide } \\
\text { infusion alone }\end{array}$ & $\begin{array}{l}\text { No difference in urine output } \\
\text { or fluid balance at } 24 \text { hours }\end{array}$ \\
\hline$[15]$ & $\begin{array}{l}\text { Retrospective } \\
\text { observational study }\end{array}$ & ICU patients & $\begin{array}{l}\text { Cases patients ( } n=30 \text { ) received at } \\
\text { least four doses of } 100 \mathrm{ml} 25 \% \text { albumin; } \\
\text { control patients }(n=25 \text { ) received no albumin }\end{array}$ & $\begin{array}{l}\text { No change in oxygenation, } \\
\text { hemodynamics; higher positive } \\
\text { fluid balance in cases }\end{array}$ \\
\hline$[19]$ & $\begin{array}{l}\text { Randomized } \\
\text { controlled trial }\end{array}$ & $\begin{array}{l}\text { Mechanically ventilated } \\
\text { patients with ARDS }(n=40)\end{array}$ & $\begin{array}{l}100 \mathrm{ml} \text { of } 25 \% \text { albumin every } 8 \text { hours } \\
\text { versus placebo; furosemide infusion }\end{array}$ & $\begin{array}{l}\text { Improved oxygenation, greater } \\
\text { net negative fluid balance, better } \\
\text { maintenance of hemodynamic } \\
\text { stability }\end{array}$ \\
\hline$[16]$ & $\begin{array}{l}\text { Prospective matched } \\
\text { case-control study }\end{array}$ & $\begin{array}{l}\text { Mechanically ventilated } \\
\text { patients with acute lung } \\
\text { injury or ARDS }\end{array}$ & $\begin{array}{l}\text { Case patients ( } n=57) \text { received } 200 \mathrm{ml} \\
\text { of } 20 \% \text { albumin and Lasix infusion; } \\
\text { control patients ( } n=57 \text { ) received usual care }\end{array}$ & $\begin{array}{l}\text { Lower net fluid balance, shorter ICU } \\
\text { stay, reduced duration of mechanical } \\
\text { ventilation; lower mortality }\end{array}$ \\
\hline
\end{tabular}

Randomized trials highlighted in bold text. $\mathrm{ADO}_{2}$, alveolar-arterial oxygen difference; ARDS, acute respiratory distress syndrome; ICU, intensive care unit. 
of diuresis obtained or serum chemistry data at 24 hours, although this may be due to the short (24-hour) course of treatment and the crossover study design. Furthermore, they did not report clinical outcomes [18]. Martin et al. [19] studied 40 mechanically ventilated patients with ARDS, and found that the addition of intravenous albumin to an infusion of furosemide, compared with furosemide infusion alone, is beneficial in patients with ARDS, resulting in improved volume of diuresis and improved oxygenation, as well as improved hemodynamic stability during diuresis [19]. In summary, there is promising, but inconclusive, evidence available to guide the use of albumin in addition to diuretics in a general ICU population.

The need for well-studied therapies to treat fluid overload in ICU patients therefore warrants a randomized controlled trial to evaluate the effectiveness of intravenous $25 \%$ albumin plus furosemide, compared with furosemide alone, in achieving improved total fluid balance, oxygenation, and hemodynamic stability at 72 hours, as well as improved ventilator-free days. Prior to embarking upon such a trial, we propose a pilot study to assess its feasibility.

\section{Study objectives Primary objective}

To determine the feasibility of conducting a randomized controlled trial in critically ill patients with hypoproteinemia and fluid overload, which will investigate the clinical effects of $25 \%$ albumin in addition to furosemide. Specific feasibility outcomes, and pre-specified criteria to determine feasibility, are outlined in Tables 2 and 3.

\section{Hypothesis}

It is feasible to conduct a randomized controlled trial in critically ill patients with hypoproteinemia to investigate the clinical effects of $25 \%$ albumin in addition to furosemide.

\section{Secondary objectives}

For this pilot study, we will assess feasibility outcomes, but also collect physiologic and clinical outcome data, including volume of diuresis, oxygenation, duration of ventilation, length of ICU stay, and mortality. However, we expect the pilot study to be underpowered to demonstrate changes in these outcomes. If the pilot study successfully demonstrates feasibility, these unblinded data will be incorporated in the planned larger trial, in a nested fashion. We hypothesize that the use of intravenous $25 \%$ albumin in addition to furosemide, as opposed to furosemide alone, increases the volume of diuresis achieved, improves oxygenation, prevents intravascular volume depletion at 72 hours, and results in more ventilator-free days.

\section{Methods/Design \\ Study design}

The FADE study is a single-center, parallel, pilot randomized controlled trial. The primary outcome is feasibility, with secondary physiologic and patient-important outcome data also being collected.

\section{Participants}

The target population is one of critically ill adults with hypoalbuminemia who are in a recovery phase of critical illness and judged by the treating physician to be volume overloaded, based on clinical findings, such as peripheral edema, delayed weaning, or chest radiographic findings of interstitial or pleural fluid. Thus, inclusion criteria include: (1) admission to ICU; (2) age $\geq 18$ years; (3) hemodynamic stability for at least 24 hours, defined as the absence of persistent ( $>1$ hour) hypotension (systolic blood pressure $<90 \mathrm{mmHg}$ ) and tachycardia (heart rate $>110$ ), not currently on vasopressors, received less than $2 \mathrm{l}$ crystalloid or colloid boluses or two units of packed red blood cells, maintenance fluids excluded; (4) hypoproteinemia, defined as serum albumin $<30 \mathrm{~g} / \mathrm{l}$, or total protein $<60 \mathrm{~g} / \mathrm{l}$; (5) clinical decision by the caregiving team to diurese at least $3 \mathrm{l}$ of net fluid balance within the next 72 hours, for any reason.

Patients will be excluded for any of the following reasons: (1) known pregnancy; (2) patient or surrogate decision maker unable or unwilling to consent to blood product administration, including albumin; (3) acute kidney injury (RIFLE criteria ' $\mathrm{F}$ ' or greater with either tripling of creatinine or creatinine $>355 \mu \mathrm{mol} / \mathrm{l}$ (with a rise of $>44$ ) or average urine output below $0.3 \mathrm{ml} / \mathrm{kg} /$ hour for 24 hours) without any improvement in the previous 24 hours, or otherwise expected to necessitate dialysis within 48 hours in the opinion of the treating physician; (4) chronic kidney injury requiring dialysis; (5) clinically documented cirrhosis; (6) clinically documented nephrotic syndrome; (7) serum sodium levels greater than $150 \mathrm{mEq} / \mathrm{l}$ or serum potassium levels less than $2.5 \mathrm{mEq} / \mathrm{l}$ that cannot be treated prior to administration of study treatment; (8) inability to measure urine output and fluid balance accurately; (9) receipt of hyperoncotic albumin within preceding 24 hours; (10) previous enrollment in this trial, or any other research studies for which co-enrollment is not permitted; (11) estimated survival or ICU stay less than 72 hours.

\section{Recruitment plans and consent process}

The study will be carried out at two different ICUs within a single tertiary care academic center (Hamilton General Hospital and the Juravinski Hospital and Cancer Centre, Hamilton, Ontario, Canada). Both sites are researchintensive and serve a high volume of general medical and surgical critically ill patients. The recruitment process is outlined in Figure 1 and Table 4. Patients will be screened 
Table 2 Variables, measures, and methods of analysis

\begin{tabular}{|c|c|c|c|c|}
\hline Outcome & Hypothesis & Outcome measure & Covariates & Methods of analysis \\
\hline \multicolumn{5}{|c|}{ Feasibility outcomes } \\
\hline $\begin{array}{l}\text { Adherence to } \\
\text { treatment }\end{array}$ & $>85 \%$ adherence & $\begin{array}{l}\text { Proportion receiving first dose of } \\
\text { study treatment within } 2 \text { hours of } \\
\text { furosemide }\end{array}$ & None & $\begin{array}{l}95 \% \text { confidence } \\
\text { interval of a } \\
\text { proportion }\end{array}$ \\
\hline $\begin{array}{l}\text { Completion of } \\
\text { treatment }\end{array}$ & $>80 \%$ completion & $\begin{array}{l}\text { Proportion receiving all six doses of } \\
\text { study treatment }\end{array}$ & None & $\begin{array}{l}95 \% \text { confidence } \\
\text { interval of a } \\
\text { proportion }\end{array}$ \\
\hline $\begin{array}{l}\text { Absence of } \\
\text { hyperoncotic } \\
\text { albumin in control } \\
\text { arm }\end{array}$ & $\begin{array}{l}>85 \% \text { in control group without } 25 \% \\
\text { albumin }\end{array}$ & $\begin{array}{l}\text { Proportion of patients assigned to } \\
\text { control receiving no } 25 \% \text { albumin }\end{array}$ & None & $\begin{array}{l}95 \% \text { confidence } \\
\text { interval of a } \\
\text { proportion }\end{array}$ \\
\hline $\begin{array}{l}\text { Randomization rate } \\
\text { of eligible patients }\end{array}$ & $>50 \%$ of eligible patients recruited & $\begin{array}{l}\text { Proportion of eligible patients } \\
\text { randomized }\end{array}$ & None & $\begin{array}{l}95 \% \text { confidence } \\
\text { interval of a } \\
\text { proportion }\end{array}$ \\
\hline $\begin{array}{l}\text { Randomization rate } \\
\text { of patients by } \\
\text { clinical site }\end{array}$ & $\begin{array}{l}\text { Average recruitment of one patient per } \\
\text { site per week }\end{array}$ & Rate of recruitment per week & None & $\begin{array}{l}\text { Average rate of } \\
\text { recruitment }\end{array}$ \\
\hline
\end{tabular}

\section{Clinical outcomes}

Primary outcome

Duration of

mechanical

ventilation

Increased number of ventilator-free days Number of ventilator-free days in treatment group

\section{secondary outcomes}

Duration of
mechanical
ventilation
Episodes
interrupting
treatment with
furosemide
Need for dialysis

Decreased duration of mechanical ventilation in treatment group

Fewer episodes of interruption in treatment group

Smaller proportion of patients requiring dialysis in treatment group during ICU stay

Length of ICU stay

ICU mortality

30-day mortality

\section{Decreased 30-day mortality in treatment} group

Physiologic outcomes
Greater increase $\mathrm{PaO}_{2} / \mathrm{FiO}_{2}$ ratio in treatment group at day 3 and day 5

Greater decrease in oxygenation index in treatment group at day 3 and day 5

Change in lung compliance

Change in fluid balance

Change in body weight
Greater increase in dynamic compliance in treatment group at day 3 and day 5

Greater net decrease in fluid balance in treatment group at day 3 and day 5

Greater decrease in body weight in treatment group at day 3 and day 5

Duration of ventilation at time of randomization

Duration of mechanical ventilation (days)

Number of episodes

Proportion of patients requiring dialysis during 30 days

Duration of ICU stay

All-cause mortality (binary)

All-cause mortality (binary)

Change in $\mathrm{PaO}_{2} / \mathrm{FiO}_{2}$ ratio

Change in oxygenation index

Change in dynamic compliance during study treatment $\left(\mathrm{ml} / \mathrm{cmH}_{2} \mathrm{O}\right)$

Change in net fluid balance ( $\mathrm{ml}$ )

Change in body weight $(\mathrm{kg})$
Duration of ventilation at time of randomization

None

None

Chi-squared or Fisher's exact statistic

Duration of ICU stay at time of randomization

APACHE-2 and SOFA scores at randomization

APACHE-2 and SOFA scores at randomization

$\begin{array}{ll}\text { None } & t \text { test } \\ \text { None } & t \text { test } \\ \text { None } & t \text { test }\end{array}$

Net fluid balance at $t$ test, linear regression time of randomization

Baseline weight $t$ test, linear regression

Kaplan-Meyer survival curve (time to death)

Kaplan-Meyer survival curve (time to death)

test

test

test t test, linear regression 
Table 2 Variables, measures, and methods of analysis (Continued)

\begin{tabular}{|c|c|c|c|c|}
\hline Urine output & $\begin{array}{l}\text { Greater net urine output in treatment } \\
\text { group at day } 3 \text { and day } 5\end{array}$ & $\begin{array}{l}\text { Urine output during } 3 \text { days of study } \\
\text { treatment }(\mathrm{ml})\end{array}$ & $\begin{array}{l}\text { Net fluid balance at } \\
\text { time of } \\
\text { randomization }\end{array}$ & $t$ test, linear regression \\
\hline Dose of furosemide & $\begin{array}{l}\text { Lower total amount of furosemide used } \\
\text { in treatment group at day } 3\end{array}$ & $\begin{array}{l}\text { Dose of furosemide during } 3 \text { days of } \\
\text { study treatment }(\mathrm{mg})\end{array}$ & None & $t$ test \\
\hline $\begin{array}{l}\text { Changes in serum } \\
\text { albumin }\end{array}$ & $\begin{array}{l}\text { Greater increase in serum albumin level } \\
\text { in treatment group at day } 3 \text { and day } 5\end{array}$ & Change in serum albumin $(\mathrm{g} / \mathrm{l})$ & None & $t$ test \\
\hline $\begin{array}{l}\text { Changes in colloid } \\
\text { osmotic pressure }\end{array}$ & $\begin{array}{l}\text { Greater increase in colloid osmotic } \\
\text { pressure in treatment group at day } 3 \\
\text { and day } 5\end{array}$ & $\begin{array}{l}\text { Change in colloid osmotic pressure } \\
(\mathrm{mmHg})\end{array}$ & None & $t$ test \\
\hline $\begin{array}{l}\text { Changes in serum } \\
\text { total protein }\end{array}$ & $\begin{array}{l}\text { Greater increase in total protein in } \\
\text { treatment group at day } 3 \text { and day } 5\end{array}$ & Change in total protein $(\mathrm{g} / \mathrm{l})$ & None & $t$ test \\
\hline $\begin{array}{l}\text { Change in } \\
\text { electrolytes }\end{array}$ & $\begin{array}{l}\text { No difference between study groups for } \\
\text { major electrolytes (sodium, potassium) at } \\
\text { day } 3 \text { and day } 5\end{array}$ & $\begin{array}{l}\text { Change in electrolytes between } \\
\text { beginning and end of study } \\
\text { treatment (mEq/l) }\end{array}$ & None & $t$ test \\
\hline \multicolumn{5}{|l|}{ Subgroup analyses } \\
\hline ARDS & $\begin{array}{l}\text { Improved oxygenation in patients with } \\
\text { ARDS }\end{array}$ & & None & $\begin{array}{l}\text { Regression methods } \\
\text { with appropriate } \\
\text { interaction term }\end{array}$ \\
\hline Severity of disease & $\begin{array}{l}\text { Improved hemodynamic stability in } \\
\text { patients with severe disease }\end{array}$ & & None & $\begin{array}{l}\text { Regression methods } \\
\text { with appropriate } \\
\text { interaction term }\end{array}$ \\
\hline $\begin{array}{l}\text { Time since recovery } \\
\text { of hemodynamic } \\
\text { stability }\end{array}$ & $\begin{array}{l}\text { Improved hemodynamic stability in } \\
\text { patients with recent hemodynamic } \\
\text { instability }\end{array}$ & $\begin{array}{l}>48 \text { hours versus }<48 \text { hours of } \\
\text { hemodynamic stability (as defined by } \\
\text { study eligibility criteria) }\end{array}$ & None & $\begin{array}{l}\text { Regression methods } \\
\text { with appropriate } \\
\text { interaction term }\end{array}$ \\
\hline \multicolumn{5}{|l|}{ Sensitivity analyses } \\
\hline $\begin{array}{l}\text { Per-protocol } \\
\text { analysis }\end{array}$ & & All outcomes & None & \\
\hline $\begin{array}{l}\text { Adjusting for } \\
\text { baseline covariates }\end{array}$ & & All outcomes & As described & $\begin{array}{l}\text { Multivariable } \\
\text { regression }\end{array}$ \\
\hline $\begin{array}{l}\text { Adjusted for dose } \\
\text { of furosemide }\end{array}$ & $\begin{array}{l}\text { Treatment with albumin results in } \\
\text { improvement beyond that explained by } \\
\text { dose of furosemide }\end{array}$ & All outcomes & Dose of furosemide & $\begin{array}{l}\text { Multivariable } \\
\text { regression }\end{array}$ \\
\hline
\end{tabular}

by study investigators within 72 hours of admission to the ICU. Patients present in the ICU for longer than 72 hours can be referred to study investigators by the team providing care if they believe that the patient might qualify for the study. Patients or surrogate decision makers will be approached by the research team and informed of the study rationale and methods, and provided with literature about the study. They will then be given an opportunity to consider study enrollment, in person or via phone. If the patient is willing, consent for the research study as well as blood product administration, if it has not already been received by the caregiving team, will be obtained. Patients

Table 3 Feasibility outcomes and estimated sample sizes

\begin{tabular}{|c|c|c|c|c|}
\hline Outcome & Demonstration of feasibility & $\begin{array}{l}\text { Estimated actual } \\
\text { proportion }\end{array}$ & $\begin{array}{l}\text { Desired } \\
\text { precision }\end{array}$ & $\begin{array}{l}\text { Required } \\
\text { sample size }\end{array}$ \\
\hline $\begin{array}{l}\text { Administration of first dose of albumin within two hours } \\
\text { of furosemide administration }\end{array}$ & $\begin{array}{l}\text { Lower-bound of } 95 \% \text { confidence } \\
\text { interval greater than } 85 \%\end{array}$ & 0.925 & 0.075 & 47 \\
\hline Administration of at full 72 hours of study treatment & $\begin{array}{l}\text { Lower-bound of } 95 \% \text { confidence } \\
\text { interval greater than } 80 \%\end{array}$ & 0.9 & 0.1 & 34 \\
\hline Absence of hyperoncotic albumin in control arm & $\begin{array}{l}\text { Lower-bound of } 95 \% \text { confidence } \\
\text { interval greater than } 85 \%\end{array}$ & 0.95 & 0.1 & 18 \\
\hline $\begin{array}{l}\text { Randomization rate of patients eligible by screening } \\
\text { criteria }\end{array}$ & $\begin{array}{l}\text { Lower-bound of } 95 \% \text { confidence } \\
\text { interval greater than } 50 \%\end{array}$ & 0.65 & 0.15 & 39 \\
\hline
\end{tabular}




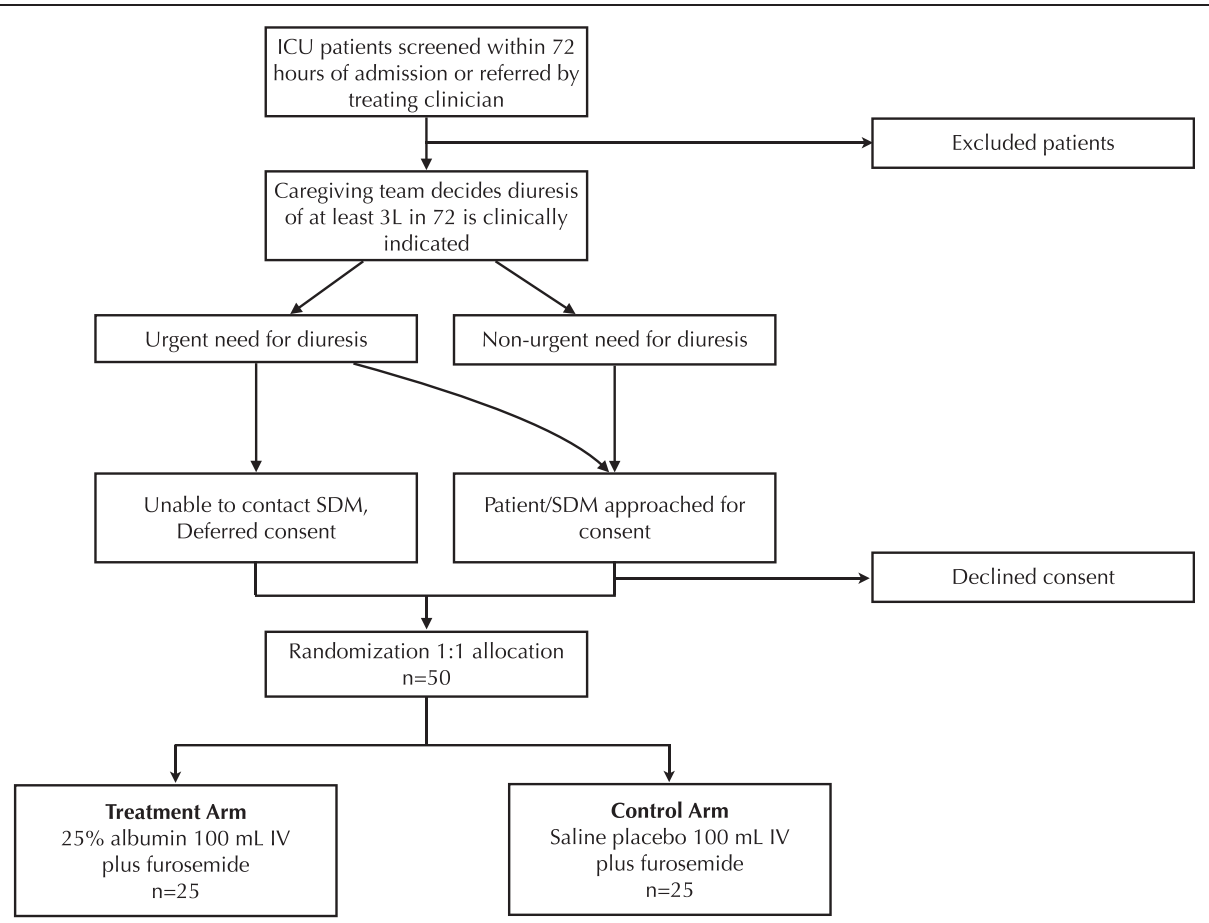

Figure 1 Patient recruitment and randomization process. ICU, intensive care unit; IV, intravenously, SDM, surrogate decision maker.

will be screened and randomized once the caregiving team decides diuresis is necessary, but prior to administering diuretics from the caregiving team.

Alternatively, if a treating physician believes that a patient might qualify for the study, and is in urgent need of diuresis, the patient can be considered for deferred consent. To be eligible for deferred consent, patients or surrogate decision makers must have already given consent for administration of blood products. Patients will then be randomized to a study arm and diuretics administered. Study investigators will try to obtain consent from the surrogate decision maker within the next 48 hours. If the surrogate decision maker cannot be located, the patient will be withdrawn from the study. Similarly, if the surrogate decision maker declines participation in the study, the participant will be withdrawn from the study. The deferred consent process is only to be used if the need for diuresis is urgent, and the surrogate decision maker cannot be reached in a timely fashion.

Many strategies have been implemented to aid in recruitment for this pilot study, including the use of recruitment posters and presentations to familiarize ICU staff in participating centers with the study aims and methods. All investigators are either critical care physicians or fellows at the two ICUs where the study is taking place and will aid in recruitment. The inclusive eligibility criteria should also facilitate timely completion of the study.

\section{Randomization}

The randomization process is outlined in Figure 1. Participants will be randomly assigned to either the control or experimental group in a 1:1 fashion with allocation concealment using an online computer generated randomization schedule. Randomization will be done at the time that the treating physician judges diuresis to be necessary. Allocation of patients to the study group will be carried out by the transfusion medicine service, who will contact a web-based randomization system set up by the statistics team. The transfusion medicine personnel responsible for assignment are distinct from the study personnel enrolling subjects in the study in the ICUs. The transfusion medicine service will keep an electronic list of patient names, study ID numbers, and treatment allocation. Study investigators will not have access to this list and will have to contact the transfusion medicine service to unblind patients for any reason, for example, suspected adverse reaction to a study treatment.

\section{Blinding}

Trial participants, care providers, data collectors, and outcome assessors will be blinded to treatment assignment. Saline placebos will be produced by the hospital's pharmacy service under sterile conditions by instilling 100 $\mathrm{ml}$ of normal saline into evacuated glass bottles identical to those used by the manufacturers of the $25 \%$ albumin. The placebos will then be stored in the transfusion 
Table 4 Schedule for enrollment, interventions, and assessments

\begin{tabular}{|c|c|c|c|c|c|c|c|c|}
\hline \multirow[b]{3}{*}{ Time point } & \multicolumn{8}{|c|}{ Study period } \\
\hline & \multirow{2}{*}{$\begin{array}{c}\text { Enrollment } \\
\text { Day -1 }\end{array}$} & \multirow{2}{*}{$\begin{array}{c}\text { Allocation } \\
0 \\
\end{array}$} & \multicolumn{5}{|c|}{ Post-allocation } & \multirow{2}{*}{$\begin{array}{c}\text { Close-out } \\
\text { Day } 30 \\
\end{array}$} \\
\hline & & & Day 1 & Day 2 & Day 3 & Day 4 & Day 5 & \\
\hline \multicolumn{9}{|l|}{ Enrollment } \\
\hline Eligibility screen & $x$ & & & & & & & \\
\hline Deferred or informed consent & $x$ & & & & & & & \\
\hline Allocation & & $\times$ & & & & & & \\
\hline \multicolumn{9}{|l|}{ Interventions } \\
\hline Treatment arm & & & $x / x$ & $x / x$ & $x / x$ & & & \\
\hline Control arm & & & $x / x$ & $x / x$ & $x / x$ & & & \\
\hline
\end{tabular}

\section{Assessments}

Baseline variables

Demographics

Past medical history

Type of diagnosis on admission

APACHE-2 score at randomization

SOFA score at randomization

Diagnosis of ARDS at randomization

Time since hemodynamic stability

Length of ICU stay at randomization

Laboratory results

Renal function tests

Serum chemistry

Serum albumin levels

Serum total protein levels

Colloid osmotic pressure

Blood gas analysis

Troponin I levels

Serum lactate levels

Complete blood count

Physiologic data

Vital signs

Glasgow Coma Scale rating

Weight

Ventilator data

Fluid intake and output

Diuretic doses and timing

Clinical outcomes

Study treatment held?

Need for dialysis?

Hypotension requiring fluids

Hypotension requiring vasopressors

Suspected infection?

Intubation status

Date of transfer from ICU

Date of death 
medicine department for use in the study. Once a patient has been randomized and assigned to a treatment group, the transfusion medicine service will cover the assigned treatment bottles with an opaque plastic sleeve and dispense them to the ICU, along with opaque intravenous tubing. Fluids will be infused into direct intravenous ports rather than distal intravenous tubing so that all study treatments will be administered directly from the covered bottles and opaque tubing without intervening clear intravenous tubing, which may threaten blinding. The opaque sleeves and intravenous tubing will allow bedside nurses to infuse the fluids without compromising blinding of themselves or the caregiving physicians. To further reduce bias of reporting, the majority of the outcomes of interest in the study are objective (that is, laboratory values, physiologic measurements), rather than subjective outcomes requiring adjudication.

To ensure the safety of study participants, a protocol for emergency unblinding exists. In the event of an adverse reaction that could be attributed to the study treatment (for example, anaphylactic reaction or transfusionrelated reaction), the study coordinators will be notified and will unmask group assignment by communicating with the third party personnel in the blood bank responsible for group allocation. Code breaks will occur only under exceptional circumstances. All code breaks (with justification) will be reported on the relevant case report forms.

\section{Interventions}

The treatment and data collection protocol is outlined in Figure 2. The placebo will be $100 \mathrm{ml}$ of normal (0.9\%) saline, administered as an intravenous infusion twice daily. This volume is negligible compared with the total fluid intake of critically ill patients (for feeds, medications, and so on), and unlikely to adversely affect study or patient outcomes, but will still provide adequate blinding of caregivers and study personnel.

The study treatment, either $100 \mathrm{ml}$ of $25 \%$ albumin or $100 \mathrm{ml}$ of saline placebo, will be administered as an infusion over 60 minutes, within 2 hours of the patient's prescribed dose of furosemide. Clinicians will be encouraged to prescribe furosemide twice daily so as to facilitate the timely administration of study treatment prior to furosemide administration.

In the event of new or worsening acute kidney injury, hypotension requiring further boluses of intravenous fluids or vasopressor agents, or if the caregiving team decides that further diuresis is unnecessary, study treatment will be held as long as the caregiving team also holds the furosemide. If a patient's serum albumin level remains greater than $35 \mathrm{~g} / \mathrm{l}$ for two measurements greater than 24 hours apart, study treatment will likewise be held. Patients will be monitored for up to 72 hours from randomization and those patients who the caregiving team decide need further diuresis, and have serum albumin levels $<35 \mathrm{~g} / \mathrm{l}$, will resume the study treatment to which they were assigned.

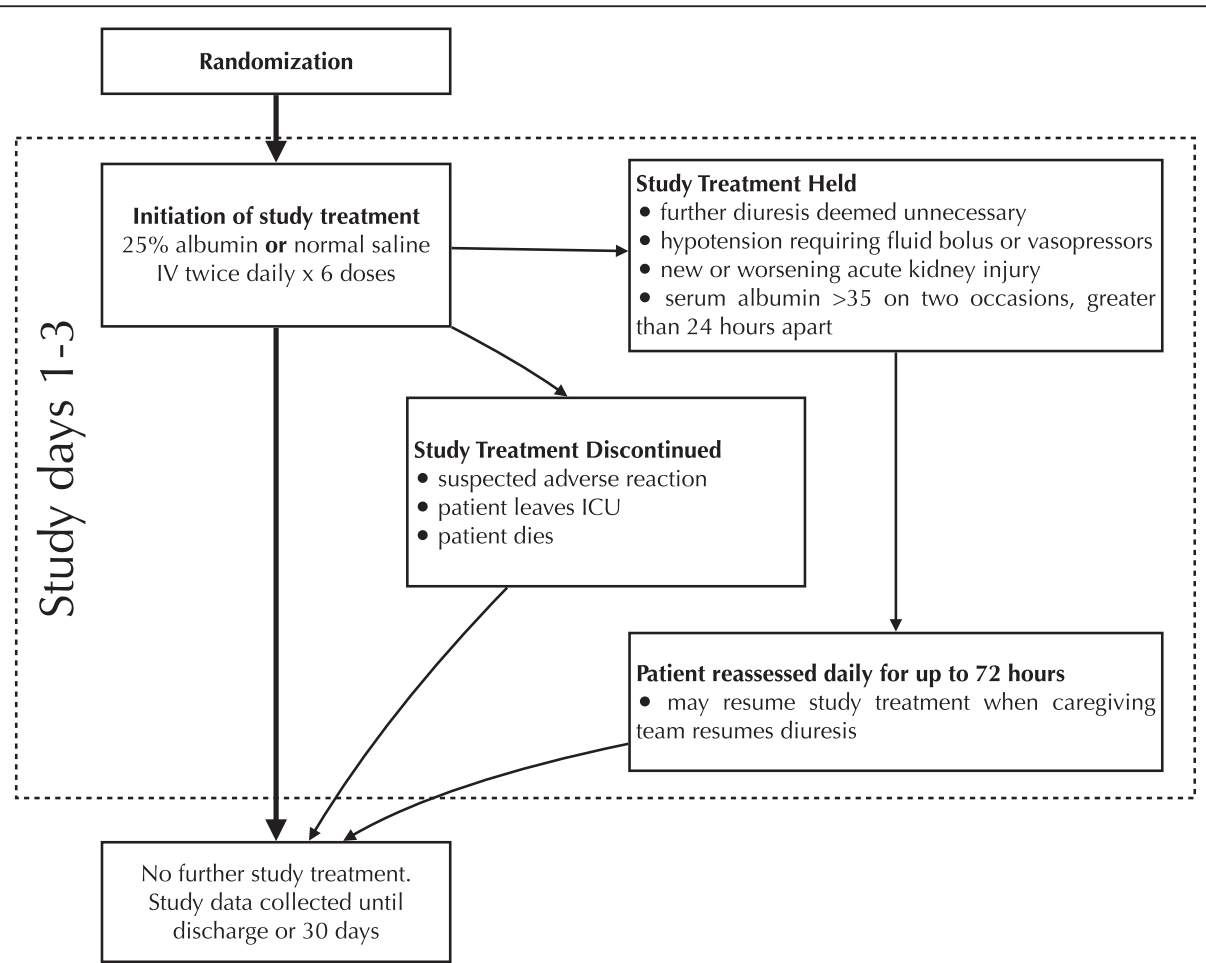

Figure 2 Patient treatment and data collection protocol. IV, intravenous. 
If the participant develops a suspected adverse reaction to either the albumin, placebo, or furosemide, or the patient leaves the ICU (is transferred to the ward, another institution, or dies) study treatment will be discontinued.

No further administration of colloid intravenous fluids (albumin or starch) will be permitted while the patient is receiving study treatment. In the event that blood product transfusion is required for low serum hemoglobin levels (as opposed to active bleeding with hemodynamic instability), one dose of the study treatment may be held and the prescribed furosemide may be given after the blood transfusion is completed, at the discretion of the caregiving team.

Nursing staff will be provided with a bedside schedule to ensure that the study drug is administered in a timely fashion and that necessary measurements are performed and blood samples collected. The short duration of treatment and the ease of study drug administration will facilitate adherence across both ICUs.

\section{Outcomes}

Outcome measures are detailed in Table 2. Our primary outcome in this pilot randomized controlled trial is feasibility, which will be assessed using five major feasibility outcomes: (1) greater than $85 \%$ adherence to protocol for randomized patients, defined as the administration of at least the first dose of study treatment (albumin or placebo) within two hours of the first administration of furosemide. This measure was chosen based on the half-life of serum albumin to increase serum colloid osmotic pressure [8]; (2) more than $80 \%$ of randomized patients receiving the full six doses of treatment study drug; (3) fewer than $15 \%$ of patients receiving non-protocolized hyperoncotic albumin administration; (4) recruitment of more than $50 \%$ of patients eligible by screening criteria; and (5) randomization rate of at least one patients by clinical site per week.

If all five criteria are met, feasibility will have been determined. Likewise, if the majority (more than three of five) of the criteria are met, and the unmet criteria could potentially be addressed with reasonable changes to the study protocol, feasibility will have been determined. If the unmet criteria cannot be addressed with changes to study protocol, or only a minority (one or two of five) of criteria are met, then non-feasibility will have been determined.

We will also collect clinical and physiologic outcome data, in anticipation of conducting a larger follow-up trial, should this study determine feasibility. The primary outcome for that trial will be the number of ventilatorfree days from time of randomization. Ventilator-free days are defined over a 28-day period, with a patient receiving one ventilator-free day for each 24 hour period spent without the need for mechanical ventilation. Patients who die during the 28 days will automatically be assigned 0 ventilator-free days [20]. This is a commonly used outcome in critical care trials, as it incorporates patientimportant outcomes of duration of mechanical ventilation and mortality, both of which have been associated with volume overload in observational studies.

The secondary clinical outcomes that we will collect data for include: (1) duration of mechanical ventilation, measured from time of randomization until extubation that is successful for 24 hours or more, recorded in days; (2) number of episodes of interrupting treatment with furosemide (for example, hypotensive episodes, renal failure, contraction alkalosis); (3) proportion of patients receiving dialysis; (4) length of ICU stay from randomization; (5) ICU mortality; and (6) 30 day mortality. We hypothesize that the addition of $25 \%$ albumin will lead to fewer interruptions of diuresis, a reduced incidence of acute kidney injury, and a shorter stay in the ICU.

The secondary physiologic outcomes that we will collect data for include: (1) changes in oxygenation $\left(\mathrm{FiO}_{2}, \mathrm{PaO}_{2} /\right.$ $\mathrm{FiO}_{2}$ ratio, oxygenation index) from baseline at day 3 and day 5; (2) changes in dynamic lung compliance, reflecting changes in extravascular lung water, at day 3 and day 5; (3) changes in total fluid balance and body weight, and amount of urine output from baseline at day 3 and day 5; (4) total dose of furosemide used, to assess whether study treatment improves the physiologic response to furosemide; (5) changes in serum albumin and colloid osmotic pressure between treatment groups from baseline at day 3 and day 5 , to ensure that the experimental treatment results in the expected increases in these measurements; (6) changes in electrolyte levels (potassium level less than 2.5 $\mathrm{mEq} / \mathrm{l}$, sodium level $>150 \mathrm{mEq} / \mathrm{l}$ ), as a way to ensure that no major, potentially harmful changes in serum electrolytes occur as a result of study treatment.

\section{Sample size calculations}

We determined that the greatest threat to the feasibility is the ability to administer the first dose of study treatment in a timely fashion, within two hours of the first administration of furosemide. As such, it was selected as the outcome used to determine our sample size. Assuming an actual adherence of $92.5 \%$, to demonstrate at least an $85 \%$ adherence, a sample size of 47 is required. Other important feasibility outcomes include the administration of 72 hours of study treatment to each patient, and the absence of hyperoncotic albumin administration in the control arm. Estimated sample sizes required to show those outcomes with the desired level of precision are shown in Table 3 .

\section{Data collection}

Data to be collected are listed in Table 4. Demographic information, prior medical conditions, and reason for 
admission to ICU will be recorded. The Acute Physiology and Chronic Health Evaluation (APACHE), and Sepsisrelated Organ Failure Assessment (SOFA) will be used at the time of ICU admission, the time of randomization, and the treatment end. The administration and doses of intravenous fluids, blood products, and diuretics will also be recorded. Data related to rationale for diuresis will also be collected (peripheral edema, pulmonary edema on chest X-ray, low urine output, elevated central venous pressures or left atrial pressures). Study outcome data collected daily will include vital signs and hemodynamics (if central venous monitoring or pulmonary artery catheters are in place), fluid balance, hourly urine output, weight, ventilator settings (if patient is ventilated), intubation status (including reasons for intubation or re-intubation), oxygenation parameters $\left(\mathrm{SaO}_{2}, \mathrm{FiO}_{2}, \mathrm{PaO}_{2} / \mathrm{FiO}_{2}\right.$ ratio, oxygenation index). Blood samples, to determine standard and extended electrolyte levels, renal profile, complete blood count with differential, serum albumin and total protein levels, and blood gas data, are routinely collected in patients undergoing diuresis and will be collected at least daily. Colloid osmotic pressure and serum total protein will also be assessed at baseline, day 3 and day 5 . Study data will be collected from the time of ICU admission to hospital discharge or 30 days after enrollment. All of these data are measured routinely in the ICU and subject to minimal interobserver variation. Colloid osmotic pressure will be measured using the Wescor model 4220, which has a precision of $\pm 0.03 \mathrm{mmHg}$ [21].

Subject data will be collected daily through examination of the patient chart, including electronic ICU charting and the Meditech laboratory reporting system. Standardized electronic case report forms will be used to collect patient and study data. Data recording will be performed using standardized case report forms in duplicate to ensure minimal human error. Data from case report forms will be entered into an electronic database on a secure computer server. Given the short time of study treatment (3 days) and intensive follow-up to 5 days, retention of study subjects is not anticipated to pose a problem. Similarly, longer-term follow-up data for our outcomes of interest (transfer from ICU, ventilatorfree days, and death) are easily retrieved from hospital records.

\section{Data management}

Data will be entered using electronic case report forms into a computerized database stored on a secure server in the Department of Epidemiology and Biostatistics at McMaster University. All collected data will be kept under secure conditions in keeping with Good Clinical Practice and McMaster University's research ethics board guidelines for a minimum of 7 years following study completion.

\section{Statistical methods}

All $P$ values will be two sided, with a level of $P \leq 0.05$ indicating statistical significance. All data will be analyzed using statistical software on an intention-to-treat basis. All randomized participants, regardless of protocol adherence, will be included in the main analysis.

Feasibility outcomes will be calculated as proportions with $95 \%$ confidence intervals, with feasibility being met if the lower-bound of the $95 \%$ confidence interval is above the level pre-specified for feasibility (Table 3). Data regarding our primary and secondary clinical outcomes will also be collected during this pilot study for future analysis; however, no analysis of clinical outcomes will be made for this pilot study, as the main purpose is to inform the definitive trial. Data collected from this pilot study will remain blinded and eventually incorporated into the dataset for the definitive trial, with the following pre-specified analyses.

Comparisons between the two treatment groups at a single time point (for example, baseline variables, number of patients requiring fluid bolus or vasopressors for hypotension, total dose of furosemide, and so on) will made using unpaired Student's $t$ test. Comparisons within a treatment group at different time points (change in serum albumin, colloid osmotic pressure, total protein, weight, fluid balance, oxygenation, lung compliance at day 3 and day 5, and so on) will be analyzed in a similar fashion. Multiple between-groups comparisons of continuous variables will be analyzed by repeated-measures analysis of variance. Linear regression will be used where appropriate to correct for baseline variables. Ventilator-free days will be defined as the number of 24-hour periods in which a patient does not need ventilation during 28 days (patients who die, by definition, will have 0 ventilator-free days). Survival analysis will be performed to assess 30-day mortality.

A-priori analyses include stratifying patients by illness severity at time of randomization (using APACHE and SOFA scores), presence of ARDS, patients admitted with sepsis, patients admitted with congestive heart failure, and time since recovery of hemodynamic stability (greater than or less than 48 hours from discontinuation of vasopressors). All subgroups carry biological plausibility for differing effects of the intervention, with the hypothesis of greater improvement in those patients with more severe illness, presence of ARDS, and shorter time since hemodynamic stability.

\section{Data monitoring and auditing}

Study participants will be closely monitored in the ICU. Suspected harms of the study treatment will be reported directly to study investigators. Case report forms will also be used to record any suspected harms and clinically important differences between treatment and control groups, 
including patient mortality, length of ICU stay, ventilatorfree days, and electrolyte abnormalities, which will be analyzed using the statistical methods outlined in Table 2. Data monitoring and quality assurance of the study will be undertaken by the investigators. The local investigator $(\mathrm{CH})$ will undertake responsibility for such duties.

Study participants may be withdrawn from the study early if there is suspicion of treatment harm by the team caring for the participant, such as an allergic reaction, worsening renal function, or worsening hypernatremia; or if consent for study therapy is withdrawn by the participant or surrogate decision maker at any time. Treating physicians cannot withdraw patients from the study, but can decide to withhold study treatment. Participants who withdraw consent to the study will be asked whether they are withdrawing from any or all of: (1) study treatment, (2) future data collection, or (3) primary outcome data collection.

Formal data monitoring will not be performed in this small pilot randomized controlled trial, owing to both its small sample size and the small risk the intervention poses to study participants. A formal data-monitoring committee will be created to oversee the larger followup trial, should this pilot study demonstrate feasibility.

\section{Research ethics approval and confidentiality}

The study protocol, written and verbal consent forms, data to be collected, and recruitment posters have been approved by the Hamilton Integrated Research Ethics Board (Project \#14-002). Any modifications of the protocol that might impact patient safety, confidentiality, or other significant conduct of the study will be reviewed by the Hamilton Integrated Research Ethics Board before implementation. Minor administrative changes will be reviewed by the investigative team but not the Hamilton Integrated Research Ethics Board.

All study information will be stored securely in locked cabinets or on secure, password-protected computer systems with limited access at the study sites. All case report form data, laboratory specimens, and administration forms will be identified with a coded identification number to maintain patient confidentiality. Records containing patient names and other identifying information will be stored in a separate locked area with limited access. No patient-identifying information will be published or released to anyone outside of the study team.

\section{Access to data}

Data management will be performed by members of the Department of Epidemiology and Biostatistics at McMaster University. The study investigators will have full access to study datasets. External requests for study data will be granted, however any information that is shared will be blinded to any identifying participant information.

\section{Ancillary and post-trial care}

Patients enrolled into the study will receive routine care from the intensive care team following completion of study treatment. Should this study, or its follow-up studies, provide evidence of the effectiveness, no further provision of treatment to participants will be required, as the study treatment is for short-term use only.

\section{Dissemination policy}

There are no stipulations on publication in place by any party, including the trial sponsors. The study investigators will publish the results of the pilot study, including feasibility outcomes and characteristics of the study cohort, should feasibility be demonstrated. Outcomes analyzed by the treatment group will only be published if non-feasibility is demonstrated; otherwise pilot outcome data will be retained for incorporation in the larger follow-up study. Attempts will be made to accomplish publication within 6 months of trial completion, and in keeping with the CONSORT guidelines for randomized controlled trial publication [22]. Authorship for publications will be in keeping with guidelines from the International Council of Medical Journal Editors [23]. Following the completion of this pilot study, and the larger, follow-up study (should this pilot demonstrate feasibility) a completely de-identified data set will be archived for sharing purposes.

\section{Discussion}

The FADE study is the first prospective randomized controlled trial to assess the use of hyperoncotic albumin in addition to diuretics in a general ICU population. Should this pilot study demonstrate feasibility, the primary outcome of the larger clinical trial will be an increase in the number of ventilator-free days, with secondary clinical outcomes of reductions in the duration of mechanical ventilation, length of ICU stay, episodes of hemodynamic instability, and mortality. The addition of $25 \%$ albumin to standard diuretic therapy is a promising treatment in the post-resuscitation care of critically ill patients with edema.

\section{Trial status}

The trial is not yet recruiting.

\section{Abbreviations}

APACHE: Acute physiology and chronic health evaluation; ARDS: Acute respiratory distress syndrome; CONSORT: Consolidated standards of reporting trials; $\mathrm{FiO}_{2}$ : Fraction of inspired oxygen; ICU: Intensive care unit; $\mathrm{PaO}_{2}$ : Partial pressure of oxygen in arterial blood; RIFLE: 'Risk, injury, failure, loss, end-stage renal disease'; $\mathrm{SaO}_{2}$ : Oxygen saturation; SOFA: Sepsis-related organ failure assessment.

\section{Competing interests}

The authors declare that they have no conflicts or competing interests. 


\section{Authors' contributions}

SJWO and IM conceived and designed the study, wrote the study protocol and grant applications, will be involved in study recruitment, and wrote and approved the final manuscript. MM designed the study, reviewed the study protocol, and critically revised and approved the final manuscript. $\mathrm{CH}$ conceived and designed study, reviewed the study protocol, will be involved in study recruitment, and critically revised and approved the final manuscript. All authors read and approved the final manuscript.

\section{Acknowledgements}

Thanks to Gary Foster and Lehana Thabane for feedback on the manuscript, case report forms, and statistical analysis. This study is supported by Hamilton Health Sciences New Investigator Fund. 25\% albumin is available without additional cost to the research team through Hamilton Health Sciences' transfusion medicine department. It is manufactured by Grifols (Mississauga, Ontario, Canada), who have no role in the funding of this trial. The design, management, analysis and reporting of the study are entirely independent of Hamilton Health Sciences and Grifols Canada.

Received: 31 March 2014 Accepted: 22 May 2014

Published: 12 June 2014

\section{References}

1. Wong JMH, Devji TS, Ali M, Cooray M, Roth-Albin K, Hassanzadeh R, Hamielec C: Organ weights at autopsy in critically ill patients. In Abstracts of the American Thoracic Society. Philadelphia, PA: American Thoracic Society; 2013 [http://www.atsjournals.org/doi/abs/10.1164/ajrccm-conference. 2013.187.1_MeetingAbstracts.A1567]

2. Boyd JH, Forbes J, Nakada T-A, Walley KR, Russell JA: Fluid resuscitation in septic shock: a positive fluid balance and elevated central venous pressure are associated with increased mortality. Crit Care Med 2011, 39:259-265.

3. Sakr Y, Vincent J-L, Reinhart K, Groeneveld J, Michalopoulos A, Sprung CL, Artigas A, Ranieri VM: Sepsis occurrence in acutely ill patients investigators: high tidal volume and positive fluid balance are associated with worse outcome in acute lung injury. Chest 2005, 128:3098-3108.

4. Vincent J-L, Sakr Y, Sprung CL, Ranieri VM, Reinhart K, Gerlach H, Moreno R, Carlet J, Le Gall J-R, Payen D, Sepsis Occurrence in Acutely III Patients Investigators: Sepsis in European intensive care units: results of the SOAP study. Crit Care Med 2006, 34:344-353.

5. National Heart Lung, and Blood Institute Acute Respiratory Distress Syndrome (ARDS) Clinical Trials Network, Wiedemann HP, Wheeler AP, Bernard GR, Thompson BT, Hayden D, de Boisblanc B, Connors AF, Hite RD, Harabin AL: Comparison of two fluid-management strategies in acute lung injury. N Engl J Med 2006, 354:2564-2575.

6. Murphy CV: The importance of fluid management in acute lung injury secondary to septic shock. Chest 2009, 136:102.

7. Hoste EA, Kellum JA: Acute renal failure in the critically ill: impact on morbidity and mortality. Contrib Nephrol 2004, 144:1-11.

8. Devji TS, Kruisselbrink RJ, Roth-Albin K, Wong JMH, Hamielec CM: Effect of intravenous fluid types on colloid osmotic pressure. In Abstracts of the American Thoracic Society. Philadelphia, PA: American Thoracic Society; 2013 [http://www.atsjournals.org/doi/abs/10.1164/ajrccm-conference.2013.187.1 MeetingAbstracts.A3949]

9. Wood A, Brater DC: Diuretic therapy. N Engl J Med 1998, 339:387-395

10. Fliser D, Zurbrüggen I, Mutschler E, Bischoff I, Nussberger J, Franek E, Ritz E: Coadministration of albumin and furosemide in patients with the nephrotic syndrome. Kidney Int 1999, 55:629-634.

11. Dharmaraj $R$, Hari $P$, Bagga A: Randomized cross-over trial comparing albumin and frusemide infusions in nephrotic syndrome. Pediatr Nephrol 2009, 24:775-782.

12. Phakdeekitcharoen $B$, Boonyawat $K$ : The added-up albumin enhances the diuretic effect of furosemide in patients with hypoalbuminemic chronic kidney disease: a randomized controlled study. BMC Nephrol 2012, 13:92.

13. Gentilini P, Casini-Raggi V, Fiore GD, Romanelli RG, Buzzelli G, Pinzani M, Villa GL, Laffi G: Albumin improves the response to diuretics in patients with cirrhosis and ascites: results of a randomized, controlled trial. J Hepatol 1999, 30:639-645.

14. Vinocur B, Artz JS, Sampliner JE: The effect of albumin and diuretics on the alveolar-arterial oxygen gradient in patients with pulmonary insufficiency. Chest 1975, 68:429.
15. Ferreira da Cunha D, Santana FH, Guiares Tachotti FJ, Freirede Carvalho da Cunha S: Intravenous albumin administration and body water balance in critically ill patients. Nutrition 2003, 19:157-158.

16. Cordemans C, De Laet I, Van Regenmortel N, Schoonheydt K, Dits H, Martin G, Huber W, Malbrain ML: Aiming for a negative fluid balance in patients with acute lung injury and increased intra-abdominal pressure: a pilot study looking at the effects of PAL-treatment. Ann Intensive Care 2012, 2(Suppl 1):S15.

17. Doungngern T, Huckleberry Y, Bloom JW, Erstad B: Effect of albumin on diuretic response to furosemide in patients with hypoalbuminemia. Am J Crit Care 2012, 21:280-286.

18. Makhoul N, Riad T, Friedstrom S, Zveibil FR: Frusemide in pulmonary oedema: continuous versus intermittent. Clin Intensive Care 1997 8:273-276

19. Martin GS, Moss M, Wheeler AP, Mealer M, Morris JA, Bernard GR: A randomized, controlled trial of furosemide with or without albumin in hypoproteinemic patients with acute lung injury. Crit Care Med 2005, 33:1681-1687

20. Schoenfeld DA, Bernard GR, ARDS Network: Statistical evaluation of ventilator-free days as an efficacy measure in clinical trials of treatments for acute respiratory distress syndrome. Crit Care Med 2002, 30(8):1772-1777.

21. Wescor Biomedical Systems: Wescor Colloid Osmometer Model 4420. Product Specifications. [http://www.wescor.com/biomedical/osmometer/ colloid.html]

22. Schulz KF, Altman DG, Moher D, CONSORT Group: CONSORT 2010 statement: updated guidelines for reporting parallel group randomised trials. BMJ 2010, 340:c332.

23. International Community of Medical Journal Editors Recommendations. [http://www.icmje.org/recommendations]

doi:10.1186/1745-6215-15-222

Cite this article as: Oczkowski et al.: Furosemide and albumin for diuresis of edema (FADE): a study protocol for a randomized controlled trial. Trials 2014 15:222.

\section{Submit your next manuscript to BioMed Central and take full advantage of:}

- Convenient online submission

- Thorough peer review

- No space constraints or color figure charges

- Immediate publication on acceptance

- Inclusion in PubMed, CAS, Scopus and Google Scholar

- Research which is freely available for redistribution 